of the National Institutes of Health, has been raising the kind of objection to focused institutes that is held by many serious biomedical researchers. Why fragment research, he argues, sensibly, just when the extraordinary interconnectedness of different diseases - for instance of the arthritis family with osteoporosis and systemic lupus erythematosus - is just becoming evident?

Typical short cycles for funding pose another obstacle to attacking the long-term, chronic diseases of the elderly. Most researchers (and doctors) prefer to work on problems that show quick, discernible results. But whether senile dementia is linked to nutrition or to early health, obviously cannot be answered in time for the next one- or three-year grant application.

Fortunately, more private benefactors are realizing that they can offer alternatives to traditional, government inspired approaches. Last week, Philippe Villiers, a Boston businessman, gave $\$ 40$ million to endow a new foundation dedicated to research and study of the elderly. Robert N. Butler, who is leaving the directorship of NIA after six years, will take a privately endowed chair as head of the country's first department of geriatrics, also privately endowed, at the Mount Sinai School of Medicine. But the profession would be better off, obviously, with some overall plan for how to address these new problems, rather than letting the whims of benefactors or the political process shape the future.

A start will be made soon by the National Academy of Sciences, which has just designated a chairman (Robert I. Berliner, dean of the Medical School at Yale) for its Committee on the Aging, now being formed under the auspices of the Institute of Medicine. It should be no surprise that the government did not see the need to fund an overall study (hence much of it will be paid for with academy funds) and that assembling the committee and subgroups has taken time. Ageing is not exactly the status-ridden scientific bandwagon that cancer was 10 years ago. But the scope of the study is very broad, ranging from the impact of the demographics on society to the needs of science and medicine, so the study will be a step in the right direction.

In his diary in exile, in 1935, Leon Trotsky wrote: "old age is the most unexpected of all things that can happen to a man". But there is nothing unexpected about the ageing of US population, and the future, greyer constituency for the results of research and for health care. If Thomas is right, biomedical scientists may have it within their power to make life more comfortable for these people - indeed for themselves in their old age. But to do this they must look the problems in the eye and face up to certain organisational and philosophical choices. One choice is for the US biomedical science community to follow the path of least resistance and set up new 'advocacy' specialities and institutes that would focus political attention on the problems of the elderly. The alternative, harder, but probably sounder, choice is to inject knowledge of, and concern for, the diseases of the elderly into all biomedical research to maximize the chances of the unexpected discovery that would lead, ultimately, to improved treatment or even cure of the diseases. Similarly, for the medical profession it would be better to make the needs of the elderly part of all medical training than to establish yet more specialities.

\section{Language of love}

\section{French scientists are under pressure to communi- cate in French. But can they afford to?}

The English edition of Scientific American used to sell only 5,000 copies a month in France. But the new French edition, Pour la Science, sells 50,000, its editor, M. Philippe Boulanger has claimed. So a mere change from one language to another increased communication tenfold.

This is what preys on the minds of those in France who wish to re-establish "French as a language of science". While French scientists rush to the microphone at conferences to address their American colleagues in English (see this issue p.784), and while more and more French scientists publish in English rather than
French ( 82 per cent of French papers were published in French in 1976 , but only 67 per cent in 1980), a hunger - and a need - for knowledge among the rest of the French nation may go forgotten. Moreover, it is from this forgotten part of the nation that the next generation of scientists, technologists and technicians will emerge. What is more, it is imperative, from the point of view of a socialist government, that the same sector of the nation should, at the very least, be equipped to play an educated role in the democratic management of science and technology in the country. Meanwhile, many French primary scientific journals are declining - the best work being published in English - while few good textbooks are now published in French, and science is almost absent from radio and television. Is this the nation destined to become the technological leader of Europe?

One can therefore sympathize with $M$. Jean-Pierre Chevènement, Minister of State for Science and Industry, when he insists that French scientific culture must be based on the French language. His version of the French nation requires it. $\mathrm{He}$ does not decry international communications. There, he is the first to acknowledge, the universalism of English is a distinct advantage. Chevènement is determined to improve national communication and in pursuit of that goal Chevènement's scientist must look not only outwards, but inwards, towards his own countrymen and his own media.

But in practice, what can the minister do? He starts with the knowledge that most French scientists are against him. Professor Alfred Kastler, France's sole Nobel physicist, is a passionate Francophone, but he puts the Anglophone argument succinctly: "If we publish in French," the argument goes "the international scientific community doesn't read us. And if we speak in French at an international conference, most of the audience leaves the room". Briefly: to make contact with Americans, to keep in touch with his field, the French scientist must speak English. There is no simple solution to the dilemma that is posed for the French scientist sympathetic towards Chevènement's proposals but having to survive in a world dominated by the English language.

Professor Kastler has recommended "taking the offensive". But there is only one real of fensive: to establish French science as a world force - just as the establishment of American science in the world (for whatever historical and economic reasons) led to the dominance of English. France can still dominate in one or two subjects - certain branches of mathematics, for example, and of social anthropology - but for the rest the battle will be arduous and the outcome must be gloomy.

Therefore, in most areas of science, French policy seems to grasp at straws. The provision of simultaneous translations at conferences has already been rejected as too expensive. The alternatives of partial translation by pre-print, transparencies or by a colleague (as now being suggested) seem artificial. In the matter of publication, to publish a paper in French as well as English is expensive and time-consuming; and will the editors of Comptes Rendues agree to become mere echoes of their counterparts on some English or American journal? Some have suggested more rigorous editing and selectivity in the French journals, and "vigorous marketing". This is a worthy proposal and can do no harm to the journals but if French scientists will not submit their best work to these journals anyhow, rigour and vigour are of little avail.

So is all lost for the French plan? Not entirely, insofar as early enthusiasms are now being tempered by reality. Certain small, but practical things are being done. Data banks and other forms of electronically stored information are being developed in French, for example, to make France independent of American data sources (there is a strategic imperative here also). And there are exercises to establish new, firmly edited journals in fields in which France does excel. Small things, perhaps, but the only practical ones. It is impossible to stage a complete revolution against English now. And as for French scientists: the measure of the success of the programme, in the end, will not be how many papers are published in French - but how many foreigners are forced to read them. 